\title{
Increased expression of CHOP and LC3B in newborn rats with bronchopulmonary dysplasia
}

\author{
MENGYUN LI, BINGTING PAN, YONGYAN SHI, JIANHUA FU and XINDONG XUE \\ Department of Pediatrics, Shengjing Hospital of China Medical University, Shenyang, Liaoning 110004, P.R. China
}

Received September 22, 2017; Accepted May 9, 2018

DOI: 10.3892/ijmm.2018.3724

\begin{abstract}
Bronchopulmonary dysplasia (BPD) seriously affects the health and prognosis of children, but the efficacy of treatments is poor. The present study aimed to examine the effects of $\mathrm{C} / \mathrm{EBP}$ homologous protein (CHOP), activating transcription factor 4 (ATF4) and microtubule-associated protein light chain $3 \beta$ (LC3B), and the interaction between CHOP and LC3B, in newborn rats with BPD. At 1, 7, 14 and 21 days, the rats in the model [fraction of inspired oxygen $\left(\mathrm{FiO}_{2}\right)=80-85 \%$ ] and control groups $\left(\mathrm{FiO}_{2}=21 \%\right.$ ) were randomly sacrificed, and lung samples were collected. Alveolar development was evaluated according to the radial alveolar count (RAC) and alveolar septum thickness. Ultrastructural changes were observed by transmission electron microscopy (TEM), the expression levels of CHOP, ATF4 and LC3B were determined by immunohistochemistry, and western blot and reverse transcription-quantitative polymerase chain reaction analyses. The co-localization of CHOP and LC3B in lung tissues was determined by immunofluorescence. The results showed that, compared with the control group, alveolarization arrest was present in the model group. The TEM observations revealed that, at 14 days, type II alveolar epithelial cell (AECII) lamellar bodies were damaged, with an apparent dilation of the endoplasmic reticulum (ER) and autophagy in cells within the model group. Between days
\end{abstract}

Correspondence to: Professor Jianhua Fu, Department of Pediatrics, Shengjing Hospital of China Medical University, 36 Sanhao Street, Heping, Shenyang, Liaoning 110004, P.R. China E-mail: fujh@sj-hospital.org

Abbreviations: BPD, bronchopulmonary dysphasia; HE, hematoxylin and eosin; RAC, radial alveolar count; TEM, transmission electron microscopy; ER, endoplasmic reticulum; ROS, reactive oxygen species; AECII, type II alveolar epithelial cells; OS, oxidative stress; FRs, free radicals; AOEs, antioxidant enzymes; PS, pulmonary surfactants; VLBW, very low birth weight; BALF, bronchoalveolar lavage fluid; UPR, unfolded protein response; APs, autophagosomes

Key words: bronchopulmonary dysplasia, autophagy, endoplasmic reticulum stress, oxidative stress, newborn rat, C/EBP homologous protein, microtubule-associated protein light chain $3 \beta$, activating transcription factor 4
7 and 14, the protein levels of ATF4, CHOP and LC3B were significantly increased in the model group. The mRNA levels of CHOP and LC3B were lower at days 7-21. CHOP and LC3B were co-localized in the cells of the lung tissues at day 14 in the model group. Pearson's correlation analysis showed that the protein levels of CHOP and LC3B-II were positively correlated in the model groups. As in previous studies, the present study demonstrated that BPD damaged the AECII cells, which exhibited detached and sparse microvilli and the vacuolization of lamellar bodies. In addition, it was found that the ER was dilated, with autophagosomes containing ER and other organelles in AECII cells; the expression levels of CHOP and LC3B-II were upregulated. CHOP and LC3B-II may have joint involvement in the occurrence and development of BPD.

\section{Introduction}

Bronchopulmonary dysplasia (BPD) is a severe and complicated chronic respiratory disease in premature infants. In the last 10 years, the morbidity rate of BPD has not decreased, despite of improvements in treatment in the neonatal intensive care unit. It has been shown that the incidence of BPD is higher in premature infants whose gestational age is $<32$ weeks and who have a lower birth weight. In a previous study, at a gestational age of $<25$ weeks, the incidence of BPD was $28.1 \%$, whereas the incidence of BPD was only $4 \%$ at a gestational age of 29-32 weeks (1), which seriously affected the quality of life and long-term prognosis of patients. With the prenatal application of glucocorticoids and the postnatal application of pulmonary surfactants (PS), the pathological changes and processes involved in the development of BPD vary. Compared with classical BPD, more recently diagnosed BPD shows the major pathological characteristics of pulmonary development arrest and pulmonary microvascular dysplasia, with predominant manifestations as follows: A decrease in the number and an increase in the volume of alveoli, simplification of alveolar structure, a reduction of alveolar septa, and abnormality of alveolar structure caused by the abnormal morphology of pulmonary microvessels; however, airway injury and fibrosis are mild (2).

At present, studies on the pathogenesis of BPD mainly involve investigating oxidative stress (OS), damage of the pulmonary epithelial barrier function and its abnormal repair following lung injury, DNA injury, and the involvement of epigenetics in this disease. A number of studies have demonstrated that OS is one of the key pathogenic mechanisms of 
BPD (3-7). OS is defined as the imbalance between oxidation and anti-oxidation in the body, i.e., the imbalance between enhanced reactive oxygen/reactive nitrogen substances and protective capacity without antioxidants (3). OS develops from reactive oxygen species (ROS) existing at a high level in vivo; in a hyperoxic environment, the level of ROS may become rapidly elevated. Several free radicals (FRs) produced by ROS, including superoxide radicals, hydrogen peroxide and hydroxy radicals, can interact with proteins, lipids and carbohydrates in cells and even DNA to cause toxicity. By contrast, ROS, as a secondary messenger, can activate a cascade reaction of proteins and regulate the expression of nuclear factor, hypoxia-inducible factor-1 $\alpha$ and nuclear factor erythroid 2-related factor 2, thus affecting the processes of cell growth and apoptosis. The OS induced by FRs and ROS may be important contributors to several neonatal diseases (3).

Studies have suggested that the expression levels of partial antioxidant enzymes (AOEs), including superoxide dismutase, catalase and glutathione peroxidase, are increased during late pregnancy, which matches the maturity of PS. However, due to the interruption of placental-fetal transfer and the deficiency of endogenous production $(4,5)$, premature infants usually lack a normal level of AOEs, and in vivo levels of ROS and FRs are higher than their anti-oxidative defense capacity. Additionally, the anti-oxidative defense systems of premature infants are immature, and thus several factors can readily increase the occurrence of OS, including malnutrition, inflammation, mechanical ventilation and infection. Hyperoxic exposure can further enhance the cascade reaction of OS, affect the activity of AOEs and cause permanent lung injury (6).

Previous studies of OS in BPD have focused on the application of antioxidants and the epigenetic changes of antioxidant genes $(3,7)$. In a study of 80 very low birth weight (VLBW) newborns with a gestational age of $<32$ weeks and a birth weight of $<1,250 \mathrm{~g}$ completed by Hsiao et al, the levels of interleukin (IL)-6, an inflammatory indicator, and 8-hydroxydeoxyguanosine (8-OHdG), an OS marker, in serum and bronchoalveolar lavage fluid (BALF) were markedly higher in patients who eventually developed BPD, compared with those in non-BPD patients. IL-6 and 8-OHdG were associated with the high prevalence of BPD. A receiver operator characteristic curve indicated that it was possible to predict the occurrence of BPD. The specificity of IL-6 and 8-OHdG in BALF was up to 77.8 and $64.4 \%$, respectively (8). In a prospective study of 44 premature infants with respiratory distress syndrome, Fabiano et al found that the expression level of glutathione in BALF was lower in patients who eventually developed BPD, compared with that in non-BPD patients, whereas the lipid hydroperoxide level was significantly higher (9). In addition, the anti-tumor necrosis factor drug, etanercept, markedly decreased the level of malondialdehyde in a rat BPD model and had an effect in preventing lung injury (10).

Several studies have indicated that antioxidants may be used to prevent and treat BPD; however, this has yet to be shown by a large number of clinical trials. According to the latest study, OS and endoplasmic reticulum stress (ERS) interact; ROS and reactive nitrogen species have mediating and regulating effects in ERS (11). Studies have revealed that ROS are closely associated with the protein folding capacity of the ER. It is estimated that $25 \%$ of ROS in cells results from the formation of the S-S bond during oxidative protein folding in the ER. The maintenance of a redox state in the ER lumen provides a unique microenvironment for, and contributes to, the formation of the $\mathrm{S}-\mathrm{S}$ bond; ROS produced in this process accumulate in the ER lumen, and a change in the redox state or the increased production of ROS directly or indirectly influences the steady state and protein folding function of the ER (12). For example, the aggregation of numerous ROS is an important factor causing incorrect protein folding in the ER. ROS can directly interact with proteins to promote the formation of S-S bonds and the breakage and degradation of carbochain polymers, finally resulting in incorrect folding and the inactivation of proteins to induce ERS (13). The above studies have suggested that the OS induced by a high level of reactive oxygen radicals is an important contributor to the incorrect protein folding observed in the ER that is followed by ERS.

Under certain physiological or pathological conditions, including OS, ERS can induce the aggregation of misfolded or unfolded proteins in the ER lumen; mild ERS can be relieved by an unfolded protein response (UPR), whereas severe ERS may induce autophagy (14-16). However, whether ERS is involved in the occurrence and development of BPD remains to be fully elucidated. Based on previous reports, hypoxia-reoxidation or ischemia-reperfusion injury can activate autophagy and induce ERS in a lung ischemia-reperfusion model (17-19). Zhang et al observed that microtubule-associated protein light chain $3 \beta$ (LC3B)-II can prevent hyperoxia-induced DNA injury of pulmonary epithelial cells through synergism in a BPD model $(20,21)$. In the present study, a BPD rat model was established, and ERS and autophagy in pulmonary epithelial cells were observed. The changes in C/EBP homologous protein (CHOP), an ERS-associated factor and LC3B, an autophagic marker, were investigated, as were the effects of ERS on the autophagy of lung tissues, and the roles of ERS and autophagy in the pathogenesis of BPD.

\section{Materials and methods}

Preparation of animal models. All animal experiments were approved by the Animal Ethics Committee of China Medical University (Shenyang, China; no. 2015PS230K), and all surgical procedures were performed under anesthesia with chloral hydrate to minimize pain of the experimental animals. A total of 45 specific pathogen-free Sprague-Dawley (SD) rats (36 females and 9 males, aged 4 weeks, 220-250 g) were purchased from the Laboratory Animal Center of China Medical University (Shenyang, China), and housed at a temperature of $22 \pm 2^{\circ} \mathrm{C}$ and a relative humidity of $60-70 \%$. All animals were mated at a female/male ratio of $4: 1$, and each pregnant SD rat was then bred independently and allowed to give birth spontaneously at a gestational age of 22 days. At $12 \mathrm{~h}$ following birth by spontaneous delivery, the newborn $\mathrm{SD}$ rats (with maternal rats) were randomly divided into two groups: Model group $(n=40)$ and control group $(n=40)$.

According to procedures established in our previous study (22), the newborn rats in the model group were placed into an oxygen chamber. The oxygen concentration, temperature and relative humidity of the oxygen chamber were maintained at $80-85 \%, 25-27^{\circ} \mathrm{C}$ and $60-70 \%$, respectively. Soda lime was 
used to absorb $\mathrm{CO}_{2}$ in the oxygen chamber to maintain the $\mathrm{CO}_{2}$ concentration $<0.5 \%$, and silica gel was used to absorb water. The oxygen concentration was monitored with a digital oxygen analyzer every day. In the control group, the newborn rats were allowed to breathe in fresh air (fraction of inspired oxygen $=21 \%$ ). The other conditions and control factors were the same as those in the model group. The oxygen chamber was opened every $24 \mathrm{~h}$ for $30 \mathrm{~min}$ to supplement food and water. The maternal rats in the model and control groups were exchanged to prevent them succumbing to oxygen poisoning.

Collection of lung samples. At 1, 7, 14 and 21 days following the start of the experiment, 20 newborn SD rats were randomly selected from each group, weighed and anesthetized by an intraperitoneal injection of $10 \%$ chloral hydrate $(3 \mathrm{ml} / \mathrm{kg})$. Thereafter, the thoracic cavity was opened, the left auricle sheared open, and a scalp needle inserted into the pulmonary artery via the right ventricle. Subsequently, $10 \mathrm{ml}$ of physiological saline was slowly injected to wash off the residual blood in the lungs, and the lungs were collected. The middle lobe of the right lung was fixed in $4 \%$ paraformaldehyde for hematoxylin and eosin (HE) staining, immunohistochemistry and immunofluorescence experiments. A $1-\mathrm{mm}^{3}$ section of lung tissue was cut from the left lung and then fixed in $2.5 \%$ glutaraldehyde for transmission electron microscopy (TEM). The remaining lung tissues were preserved in a $-80^{\circ} \mathrm{C}$ refrigerator for protein and $\mathrm{mRNA}$ analyses.

Pathological changes of lung tissues. The tissues were observed following HE staining under an optical microscope (H600L; Nikon Corporation, Tokyo, Japan). The left lung tissues were fixed in $4 \%$ paraformaldehyde for $24 \mathrm{~h}$, dehydrated with gradient alcohols, vitrified with xylene, embedded with paraffin, and routinely cut into $4-\mu \mathrm{m}$ thick paraffin tissue sections. Thereafter, the tissue sections were deparaffinized, hydrated, stained with HE and observed under a light microscope. The cytoplasm and collagen fibers were colored pink and nuclei were blue. For animals in each group, six sections were randomly selected at various time-points, and 10 randomly selected fields in each section were observed for recording of any pathological changes.

Alveolar development was evaluated according to a radial alveolar count (RAC) and the alveolar septum thickness. For the RAC, referring to the method of Cooney and Thurlbeck, a vertical line was plotted from the center of the respiratory bronchiole to the closest fibrous septum (or pleura), and the number of alveoli counted on the vertical line was designated the RAC (23). A high RAC indicated more mature alveolar development. The HE-stained sections were observed under the $100 \mathrm{X}$ high power lens of a light microscope; 10 sections were selected from each group at various time-points, and counting was performed three times in each section, with the results averaged. The counts were completed by two double-blinded independent pathological investigators. The alveolar septum thickness was measured according to the method used in our preliminary study (24), and the analysis was performed using a light microscope image analysis system. Six sections were randomly selected from each group at various time-points, and 10 randomly selected fields were observed in each section under the 400X high power lens of a light microscope; the alveolar septum thickness was measured in each field and the average result calculated. The measurements were completed by two double-blinded independent pathological investigators.

Ultrastructural observation of lung tissues. Ultrastructure changes in type II alveolar epithelial cells (AECII) were observed using transmission electron microscopy (TEM; H-600; Hitachi, Ltd., Tokyo, Japan). The fresh lung tissues were fixed first with $2.5 \%$ glutaraldehyde and then with $1 \%$ osmic acid, dehydrated with acetone, soaked and embedded with epoxy resin, polymerized for $72 \mathrm{~h}$, and cut into ultrathin sections $(60 \mathrm{~nm})$. Thereafter, the sections were double-stained with uranyl acetate and lead nitrate, and then observed under TEM for ultrastructure changes and the autophagy of AECII and organelles in lung tissues, with images captured.

Immunohistochemistry. The paraffin sections of lung tissues on slides were heated in a $60^{\circ} \mathrm{C}$ oven for $30 \mathrm{~min}$, routinely deparaffinized, hydrated with gradient alcohols and washed with phosphate-buffered saline (PBS). Subsequently, 3\% $\mathrm{H}_{2} \mathrm{O}_{2}$ was added to eliminate endogenous peroxidases, and the slides were incubated at $37^{\circ} \mathrm{C}$ for $20 \mathrm{~min}$. Sodium citrate buffer was added for antigen retrieval by microwave for $30 \mathrm{~min}$, following which the slides were cooled to room temperature and washed with PBS. Thereafter, $50 \mu 1$ of goat serum (cat. no. SPN-9001,9002; Zhongshan Golden Bridge Biotechnology Co., Ltd., Beijing, China) was added as a blocking agent, and the slides were incubated at $37^{\circ} \mathrm{C}$ for $45 \mathrm{~min}$. The serum was then discarded, and $50 \mu \mathrm{l}$ of the following primary antibodies were added to each slide: CHOP (cat. no. ab11419, 1:200 dilution; Abcam, Cambridge, UK), LC3B (cat. no. 3868s, 1:3,000 dilution; Cell Signaling Technology, Inc., Danvers, MA, USA). The slides were incubated with the antibodies overnight at $4^{\circ} \mathrm{C}$, and rewarmed for $45 \mathrm{~min}$. Goat anti-mouse/anti-rabbit IgG and horseradish peroxidase-labeled streptavidin (cat. no. SPN-9001, 9002, 1:300 dilution; Zhongshan Golden Bridge Biotechnology Co., Ltd.) were added in sequence, and the slides were incubated at $37^{\circ} \mathrm{C}$ for $20 \mathrm{~min}$, following which the slides were washed with PBS, and developed with DAB under a light microscope until brown-yellow particles were observed in the nuclei or cytoplasm. The slides were then washed with tap water, counterstained with hematoxylin for $5 \mathrm{~min}$, blued with running water for $30 \mathrm{~min}$, dehydrated with gradient alcohols, vitrified with xylene, and mounted with neutral balsam. PBS was used as a negative control instead of primary antibody. The immunohistochemical kits (including goat serum, Goat anti-mouse/anti-rabbit IgG and peroxidase-labeled streptavidin) were purchased from ZSGB-BIO (cat. no. SPN-9001, 9002; Zhongshan Golden Bridge Biotechnology Co., Ltd.).

Western blot analysis. Total proteins were extracted from lung tissues using RIPA (Beyotime Institute of Biotechnology, Haimen, China) and quantified using a BCA protein assay kit (Beyotime Institute of Biotechnology), following with $5 \mathrm{X}$ loading buffer was added and samples were boiled at $100^{\circ} \mathrm{C}$ for $5 \mathrm{~min}$ to complete protein denaturation. A $12 \%$ SDS polyacrylamide gel was prepared. Equal quantities of protein samples (50 $\mu \mathrm{g} /$ lane) were added to each well, subjected to electrophoresis at $100 \mathrm{~V}$ for $3 \mathrm{~h}$ and then transferred onto a polyvinylidene fluoride (PVDF) membrane (EMD Millipore, 
Billerica, MA, USA) at $100 \mathrm{~V}$ for $30 \mathrm{~min}$. Subsequently, the PVDF membrane was blocked with defatted milk diluted with 5\% TBS-T [100 mM Tris base (pH 7.5), 0.9\% (wt/vol) $\mathrm{NaCl}, 0.1 \%$ \{vol/vol) Tween-20] at room temperature for $1 \mathrm{~h}$. The following primary antibodies were then added: Rabbit anti-ATF4 antibody (cat. no. ab184904, 1:500 dilution; Abcam), mouse anti-CHOP antibody (cat. no. ab11419, 1:500 dilution; Abcam), rabbit anti-LC3B antibody (cat. no. NB100-2220, 1:200 dilution; Novus Biologicals, Littleton, CO, USA) and GAPDH antibody (cat. no. 10494-1-AP, 1:4,000 dilution; Wuhan Sanying Biotechnology, Wuhan, China) and incubated overnight at $4^{\circ} \mathrm{C}$. The PVDF membrane was washed three times with TBS-T for $10 \mathrm{~min}$, followed by incubation with horseradish peroxidase-conjugated secondary antibody (goat anti-mouse and anti-rabbit IgG-HRP; cat. nos. SA00001-1 and SA00001-2, respectively; 1:5,000 dilution; Wuhan Sanying Biotechnology), at room temperature for $2 \mathrm{~h}$, and washing three times with TBS-T for 10 min. Finally, Super ECL Plus (Thermo Fisher Scientific, Inc., Waltham, MA, USA) was added, and luminescence analysis was performed with a chemiluminescence imaging system (C300; Azure Biosystems, Dublin, CA, USA). The bands were standardized according to GAPDH.

Immunofluorescence. A double immunofluorescence labeling method was used. The paraffin lung tissue sections on slides were heated in a $60^{\circ} \mathrm{C}$ oven for $30 \mathrm{~min}$, routinely deparaffinized and hydrated with graded alcohols. Citrate buffer solution was added for microwave antigen retrieval, and subsequently cooled to room temperature. The tissue sections were blocked with goat serum (cat. no. SPN-9001; Zhongshan Golden Bridge Biotechnology Co., Ltd.) for $45 \mathrm{~min}$, and incubated with mouse anti-rat CHOP (cat. no. ab11419, 1:50 dilution; Abcam) and rabbit anti-rat LC3B (cat. no. 3868s, 1:50 dilution; Cell Signaling Technology, Inc.), antibodies overnight at $4^{\circ} \mathrm{C}$. Subsequently, fluorescent-labeled donkey anti-mouse IgG (cat. no. ab150105, 1:200 dilution; Abcam) and donkey anti-rabbit IgG (cat. no. ab150076, 1:200 dilution; Abcam) were added, incubated at room temperature for $4 \mathrm{~h}$, washed with PBS, stained with DAPI (Sigma-Aldrich; EMD Millipore) for 5 min, and washed again with PBS. The slides were observed under a confocal laser-scanning microscope (Nikon C1 system; Nikon Corporation). Positive cells exhibited green nuclei, and a red cytoplasm and cell membrane. For the negative control, PBS was used instead of primary antibody.

RNA extraction. Total RNA was extracted according to the manufacturer's protocol (Takara Bio, Inc., Otsu, Japan). The right lung tissues were placed into an Eppendorf tube and then sheared on ice. TRIzol (Takara Bio, Inc.) was added to each sample, which was then repeatedly aspirated with a sample injector to form an emulsion. Chloroform (200 $\mu \mathrm{l})$ was then added, and the sample was mixed evenly, incubated at room temperature for $5 \mathrm{~min}$, and centrifuged $(12,000 \mathrm{x} \mathrm{g})$ at $4^{\circ} \mathrm{C}$ for $15 \mathrm{~min}$. The supernatant was collected, the same volume of isopropanol added, the sample mixed evenly, and centrifuged $(12,000 \mathrm{x} \mathrm{g})$ at $4^{\circ} \mathrm{C}$ for $15 \mathrm{~min}$. The supernatant was carefully removed by pipetting to leave behind a white precipitate. Alcohol (500 $\mu 1,70 \%)$ was added and mixed evenly, and the sample was centrifuged $(7,500 \mathrm{xg})$ at $4^{\circ} \mathrm{C}$ for $5 \mathrm{~min}$. The supernatant was removed, $500 \mu 1$ of $70 \%$ alcohol was added,
Table I. Primer sequences used for reverse transcription-quantitative polymerase chain reaction analysis.

Primer

name

Primer sequence

$\begin{array}{ll}\text { ATF4 } & \text { F: 5'-CCTTCGACCAGTCGGGTTTG-3' } \\ & \text { R: 5'-CTGTCCCGGAAAAGGCATCC-3' } \\ \text { CHOP } & \text { F: 5'-AGGAGAGAGAAACCGGTCCAA-3' } \\ & \text { R: 5'-GGACACTGTCTCAAAGGCGA-3' } \\ \text { LC3B } & \text { F: 5'-ACCAGCACCCCAGCAAGA-3' } \\ & \text { R: 5'-CAGGACAGGCAGCTGCTTCT-3' } \\ \text { GAPDH } & \text { F:5'-GTATGACTCTACCCACGGCAAGTTC-3' } \\ & \text { R: 5'-AGCCTTCTCCATGGTGGTGAAGAC-3' }\end{array}$

F, forward; R, reverse; ATF4, activating transcription factor 4; CHOP, $\mathrm{C} / \mathrm{EBP}$ homologous protein; $\mathrm{LC} 3 \mathrm{~B}$, microtubule-associated protein light chain $3 \beta$.

and the sample was mixed evenly and centrifuged (7,500 x g) at $4^{\circ} \mathrm{C}$ for $5 \mathrm{~min}$. The sample was then dried at room temperature for 15 min following removal of the supernatant, and DEPC-treated water was added to dissolve the RNA precipitate. The OD260/OD280 was measured with a spectrophotometer; the concentration of RNA extracted was calculated, and the purity range was evaluated as 1.8-2.0. Finally, each RNA sample was adjusted to the same concentration $(1,000 \mathrm{ng} / \mu \mathrm{l})$.

Reverse transcription-quantitative polymerase chain reaction (RT-qPCR) analysis. RNA ( $2 \mu \mathrm{l})$ was pipetted from various samples and then reverse transcribed into cDNA using a reverse transcription system (SuperScript III; Invitrogen; Thermo Fisher Scientific, Inc.) and a PrimeScript ${ }^{\mathrm{TM}}$ RT reagent kit (RR047A; Takara Bio, Inc.) removal of genomic DNA (1 $\mu$ l gDNA Eraser, $2 \mu 1$ 5X gDNA Eraser Buffer, $2 \mu 1$ RNA, $5 \mu$ l RNase Free $\mathrm{dH}_{2} \mathrm{O}$ ) with the conditions of room temperature for $15 \mathrm{~min}$, and then reverse transcription reaction (add to the above mixture: $4 \mu \mathrm{l}$ 5X PrimeScript Buffer 2, $4 \mu \mathrm{l}$ RNase Free $\mathrm{dH}_{2} \mathrm{O}, 1 \mu \mathrm{l}$ PrimeScript RT Enzyme Mix1 and $1 \mu \mathrm{l}$ RT Primer Mix, total $20 \mu \mathrm{l}$ ) with the conditions of $37^{\circ} \mathrm{C}$ for $15 \mathrm{~min}$, and $85^{\circ} \mathrm{C}$ for $5 \mathrm{sec}$. A 7500 Real-Time PCR system (Applied Biosystems; Thermo Fisher Scientific, Inc.) and PCR amplification kit (Takara Biotechnology Co., Ltd.) were used. Adding $10 \mu \mathrm{l}$ TB Green Premix Ex Taq (Tli RNaseH Plus) (2X), $0.4 \mu \mathrm{l}$ forward primer, $0.4 \mu \mathrm{l}$ reverse primer, $2 \mu \mathrm{l} \mathrm{cDNA}$, $0.4 \mu \mathrm{l}$ ROX Reference Dye II, $6.8 \mu \mathrm{l}$ RNase Free $\mathrm{dH}_{2} \mathrm{O}$, total $20 \mu \mathrm{l}$. The reaction conditions were as follows: $95^{\circ} \mathrm{C}$ for $30 \mathrm{sec}, 95^{\circ} \mathrm{C}$ for $5 \mathrm{sec}, 60^{\circ} \mathrm{C}$ for $34 \mathrm{sec}, 95^{\circ} \mathrm{C}$ for $15 \mathrm{sec}, 60^{\circ} \mathrm{C}$ for $1 \mathrm{~min}, 95^{\circ} \mathrm{C}$ for $30 \mathrm{sec}$, and $60^{\circ} \mathrm{C}$ for $15 \mathrm{sec}$, for a total of 40 cycles. Gene-specific primers were designed and synthesized by Takara Biotechnology Co., Ltd. A dissolution curve was used to guarantee the specificity of PCR products, and the relative expression levels of target genes were normalized to GAPDH and evaluated using the $2^{-\Delta \Delta \mathrm{Cq}}$ method (25). The primer sequences used are listed in Table I.

Statistical analysis. SPSS 21.0 software (IBM SPSS, Armonk, NY, USA) was used for statistical analysis. The data are 

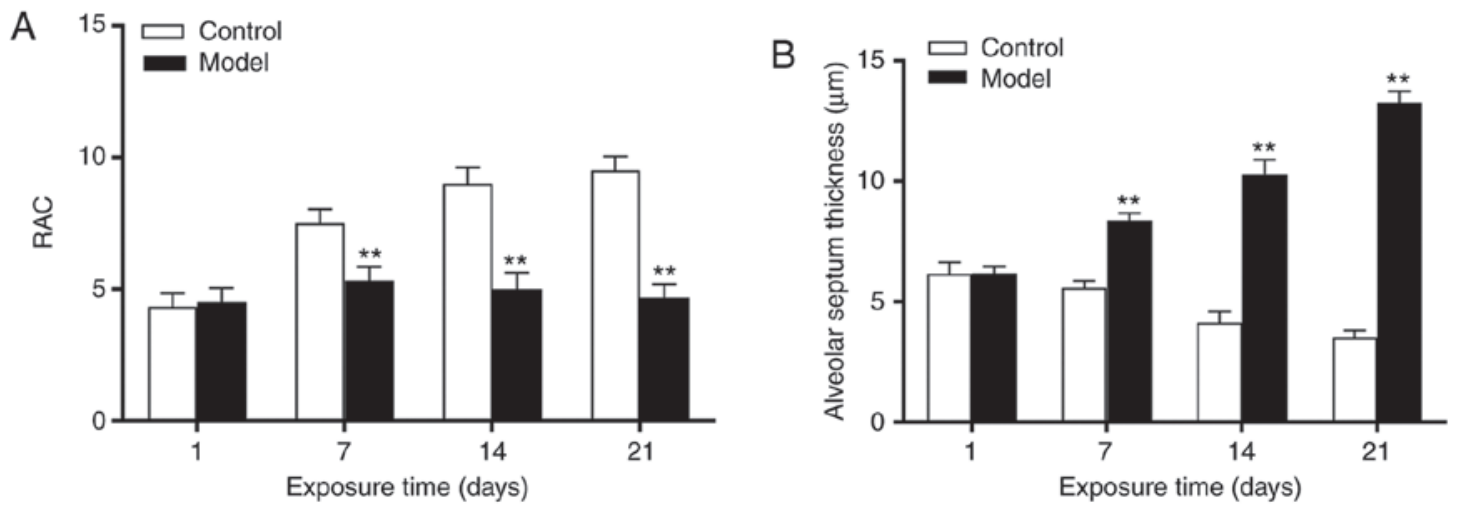

Figure 1. Evaluation of lung development according to the RAC and alveolar septum thickness. (A) RAC comparison between two groups. (B) Alveolar septum thickness comparison between two groups. ${ }^{* *} \mathrm{P}<0.01$, compared with the control group. RAC, radial alveolar count.

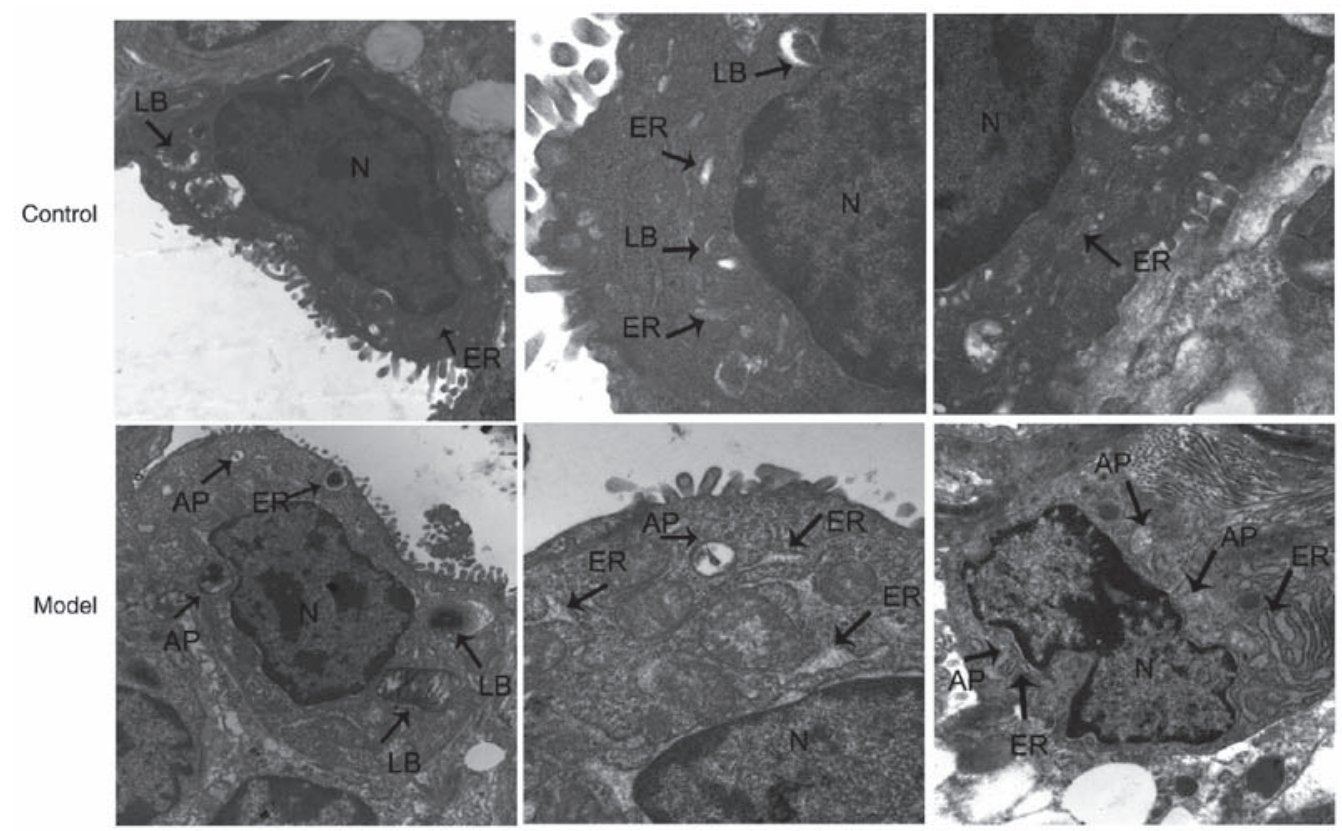

Figure 2. Transmission electron microscopy observation of AECII ultrastructure at 14 days (magnification, x50,000). In the control groups, AECII cells and their organelles appeared normal. In the model groups, apical microvilli were sparse and detached, lamellar bodies in the cytoplasm were damaged, and the ER was markedly dilated and surrounded by autophagosomes. AECII, type II alveolar epithelial cell; LB, lamellar body; AP, autophagosome; ER, endoplasmic reticulum; N, AECII nucleus.

presented as the mean \pm standard deviation. The inter-group comparison was performed using two independent samples t-test, and multiple comparisons by one-way analysis of variance. Correlation analysis of the protein expression of CHOP and LC3B-II was performed using Pearson's correlation analysis. $\mathrm{P}<0.05$ was considered to indicate a statistically significant difference.

\section{Results}

Evaluation of lung development. At day 1, there was no significant difference in the RAC between the control and model groups $(\mathrm{P}>0.05)$. Between 7-21 days, the RAC continuously decreased, and a significant difference between the two groups was noted ( $\mathrm{P}<0.01$; Fig. $1 \mathrm{~A})$. No significant difference was observed in the alveolar septum thickness between the two groups at 1 day $(\mathrm{P}>0.05)$; however, this was increased at
7 days $(\mathrm{P}<0.01)$, and reached a peak at 21 days $(\mathrm{P}<0.01)$ in the model group (Fig. 1B).

Ultrastructural changes of AECII in lung tissues. Using TEM, the AECII cells of the control group were observed to be cuboidal in shape and with apical microvilli. Within their cytoplasm, characteristic lamellar bodies, and ER, mitochondria and other organelles were present with a normal structure. In the model group, the nuclear chromatins of AECII cells were marginally aggregated, with apical microvilli that were sparse and detached. Lamellar bodies in the cytoplasm were damaged and vacuolized, the mitochondria was swollen, and the ER was markedly dilated, degranulated and pool-shaped, and was surrounded by autophagosomes (APs). Visible cytoplasmic components were contained in the vacuole-like structure of an AP double-layered membrane, including mitochondria, ER and ribosomes. APs surrounded the dilated ER (Fig. 2). 


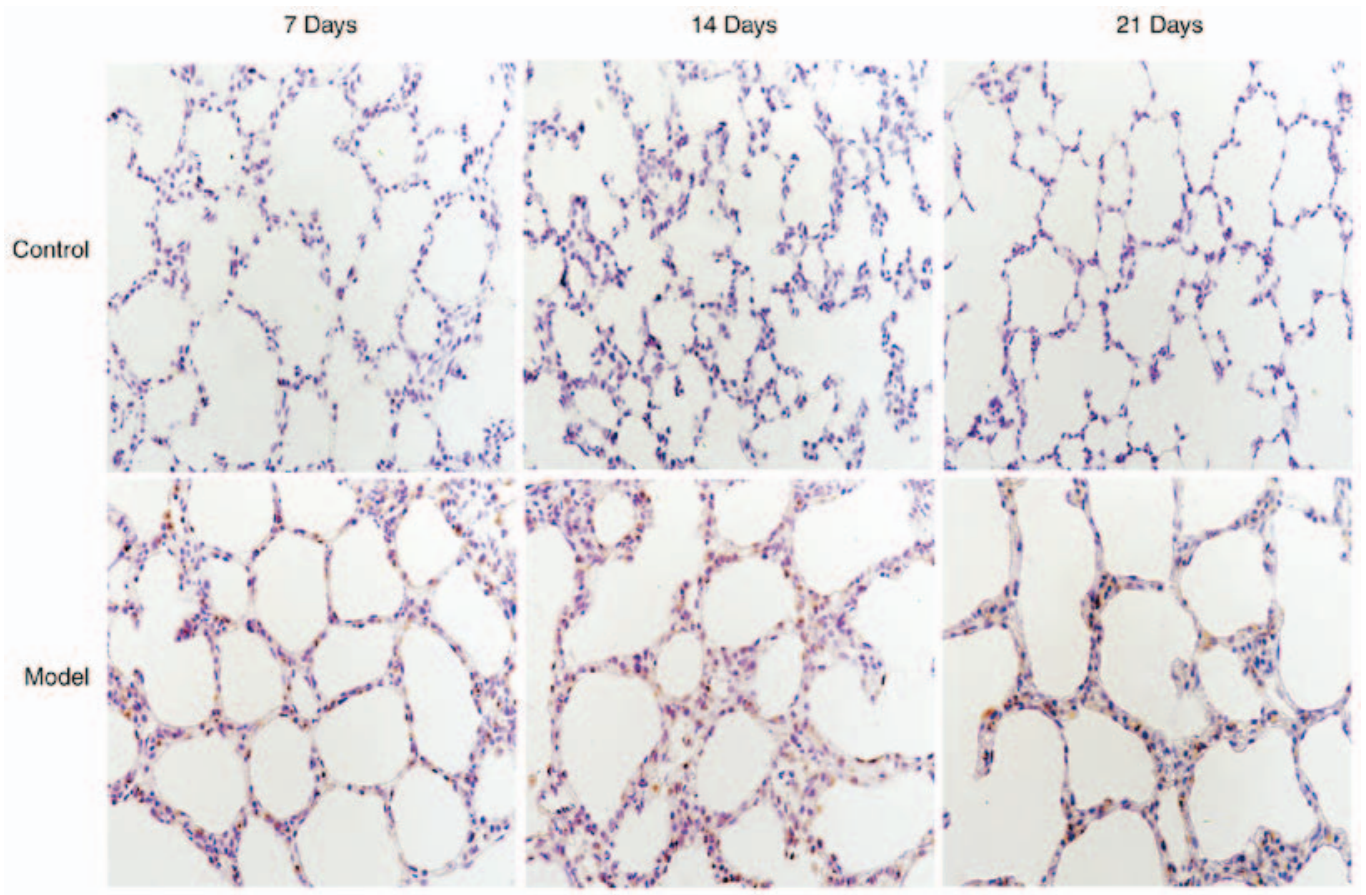

Figure 3. Detection of the expression of CHOP protein in lung tissues within control and model groups at different time-points by immunohistochemistry (magnification $\mathrm{x} 400$ ). The positively stained cells were colored brown-yellow. CHOP protein was mainly expressed in the nucleus. CHOP, C/EBP homologous protein.

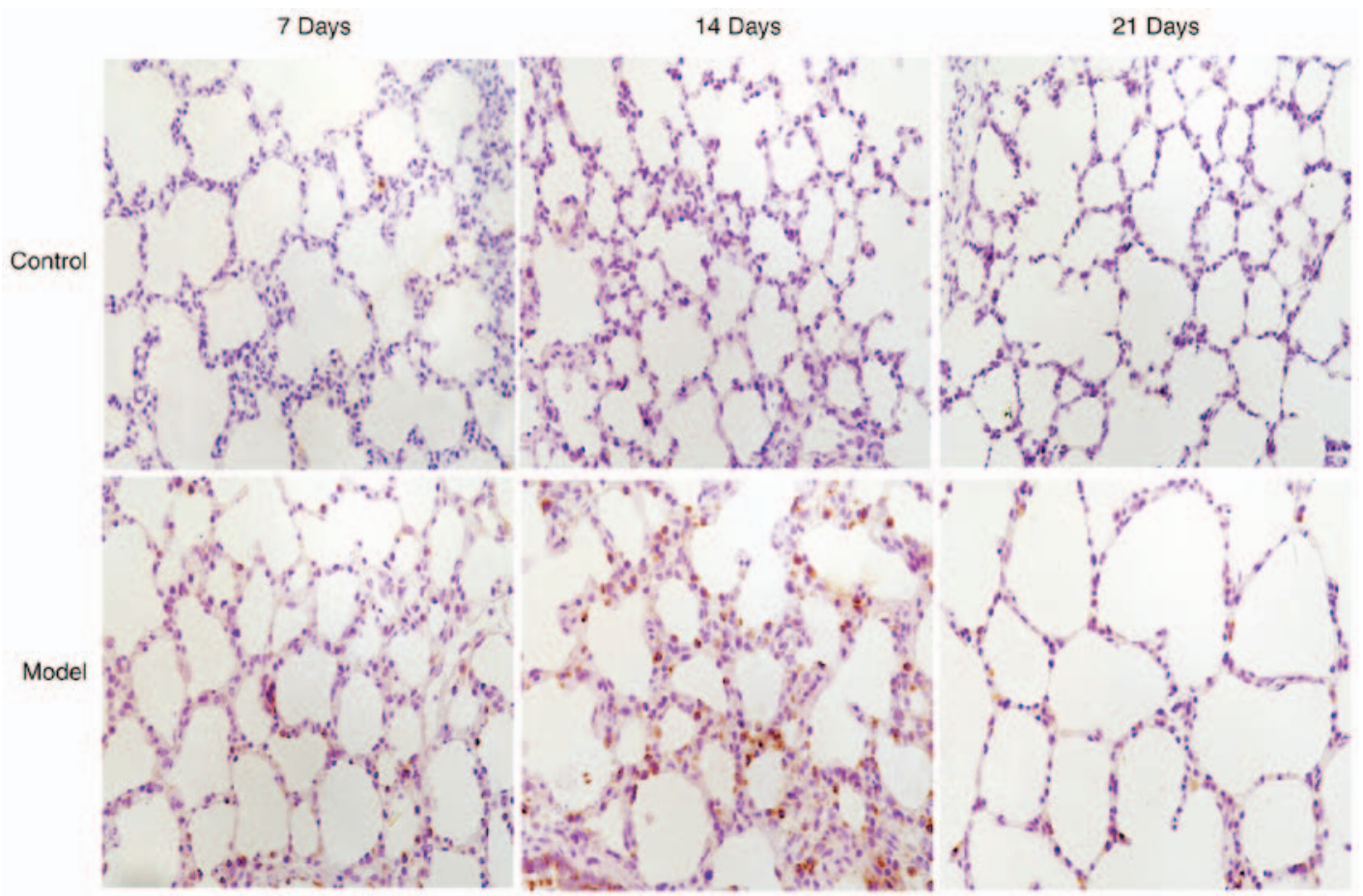

Figure 4. Detection of the protein expression of LC3B in lung tissues within control and model groups at different time-points by immunohistochemistry (magnification, $\mathrm{x} 400$ ). The positively stained cells were colored brown-yellow. LC3B protein was primarily expressed within granules in the cytoplasm. LC3B, microtubule-associated protein light chain $3 \beta$.

Localization of CHOP and LC3B in lung tissues by immunohistochemistry. In the control group, LC3B protein was mainly expressed in the cytoplasm of bronchial epithelial cells; however, CHOP protein was not expressed. In the model group, CHOP protein (Fig. 3) was predominantly located in the nuclei of alveolar and bronchial epithelial cells, and LC3B protein was aggregated in a granular and punctiform manner in the cytoplasm (Fig. 4).

Expression of ATF4, CHOP and LC3B proteins in rat lung tissues. At day 1, no statistically significant differences were noted in the protein expression levels of ATF4, CHOP or 

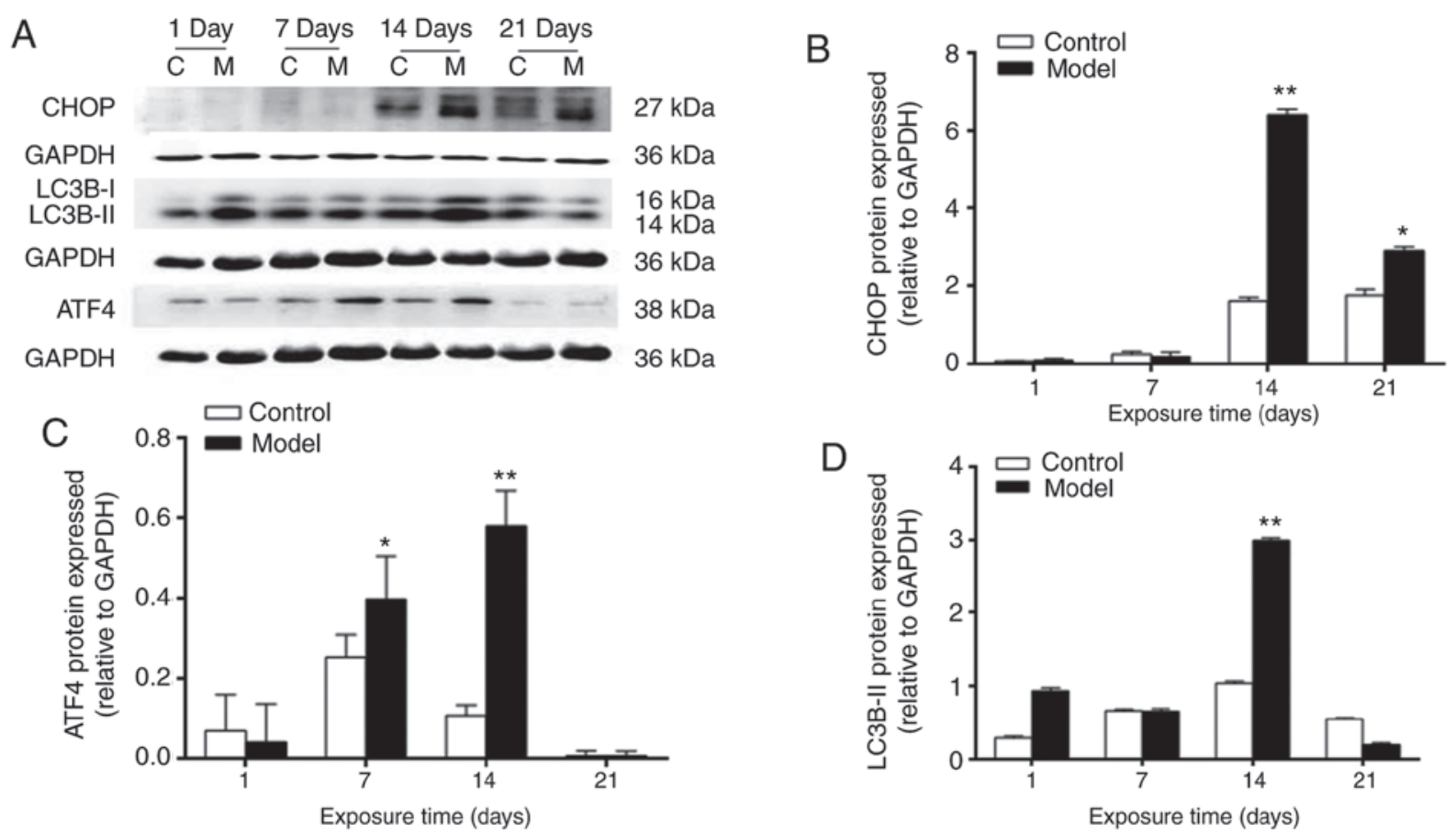

Figure 5. Expression levels of CHOP, LC3B-II, ATF4 and GAPDH in lung tissues. (A) Western blots of CHOP, LC3B-II, ATF4 and GAPDH in lung tissues. (B) Relative expression level of ATF4. (C) Relative expression level of CHOP. (D) Relative expression level of LC3B-II. "P<0.05 and "P<0.01, compared with the control group. CHOP, C/EBP homologous protein; LC3B, microtubule-associated protein light chain 3ß; ATF4, activating transcription factor 4; C, control; $\mathrm{M}$, model.

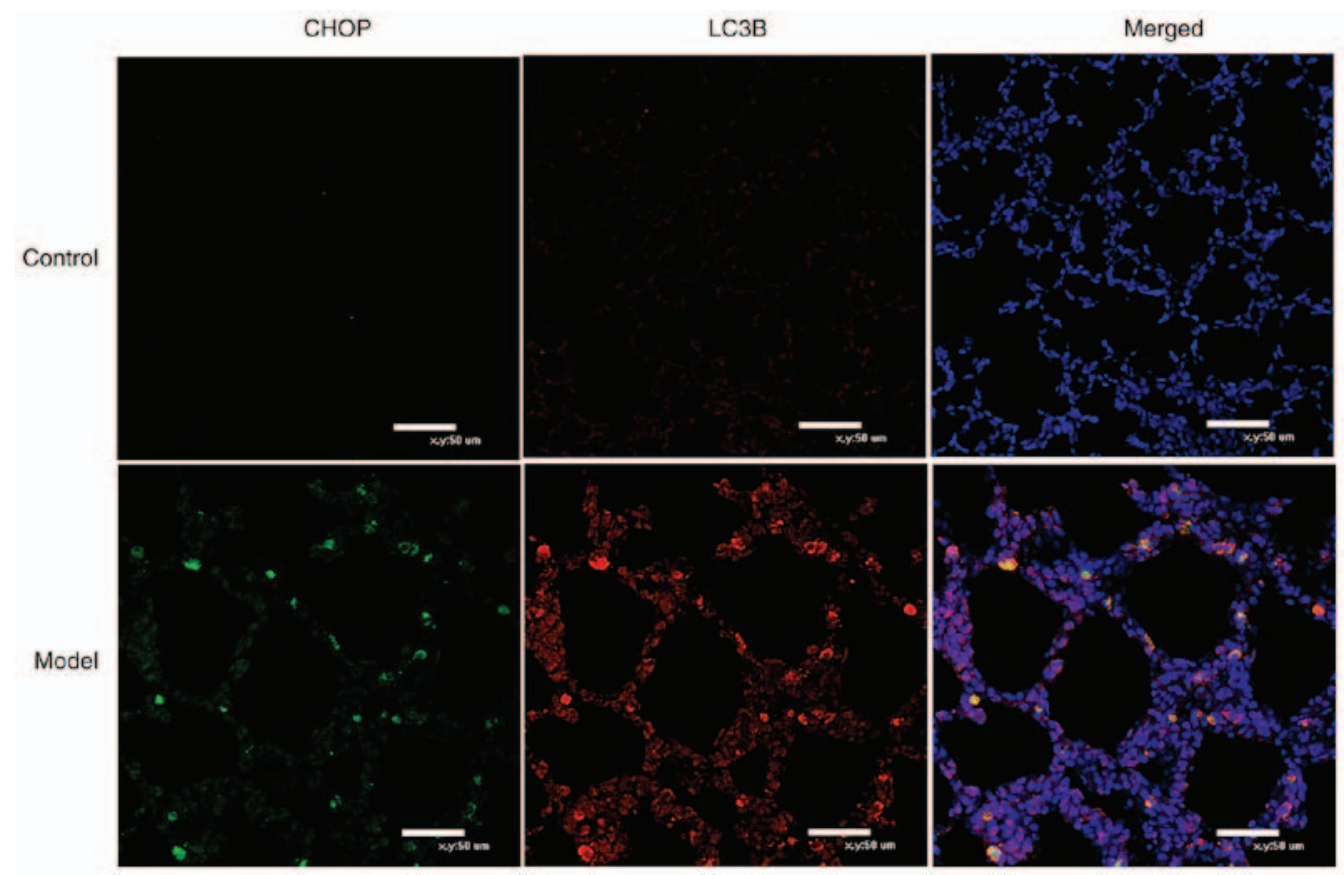

Figure 6. Double immunofluorescence staining of CHOP and LC3B proteins in lung tissues (magnification, $\mathrm{x} 400$ ). The two markers were co-expressed in cells of the model but not control group (green, CHOP; red, LC3B). CHOP, C/EBP homologous protein; LC3B, microtubule-associated protein light chain 3ß.

LC3B-II between control and model groups $(\mathrm{P}>0.05)$. The protein expression levels of ATF4, CHOP and LC3B-II were significantly higher in the model group, compared with those in the control group at 7 days, reached a peak at 14 days (ATF4, CHOP and LC3B-II, $\mathrm{P}<0.01$ ) and were marginally decreased at 21 days (CHOP, $\mathrm{P}<0.05$; ATF4 and LC3B-II, P $>0.05)$. They showed a consistent overall trend of change (Fig. 5A-D).
Co-localization of $C H O P$ and $L C 3 B$ in rat lung tissues by immunofluorescence. In the control group at 14 days, LC3B, as represented by red fluorescence, was sparsely distributed in the alveolar walls and septa of lung tissues. Minimal green fluorescence-labeled CHOP was evident and the two markers were not co-expressed. In the model group, LC3B and CHOP were co-expressed in the cytoplasm of certain cells (Fig. 6). 

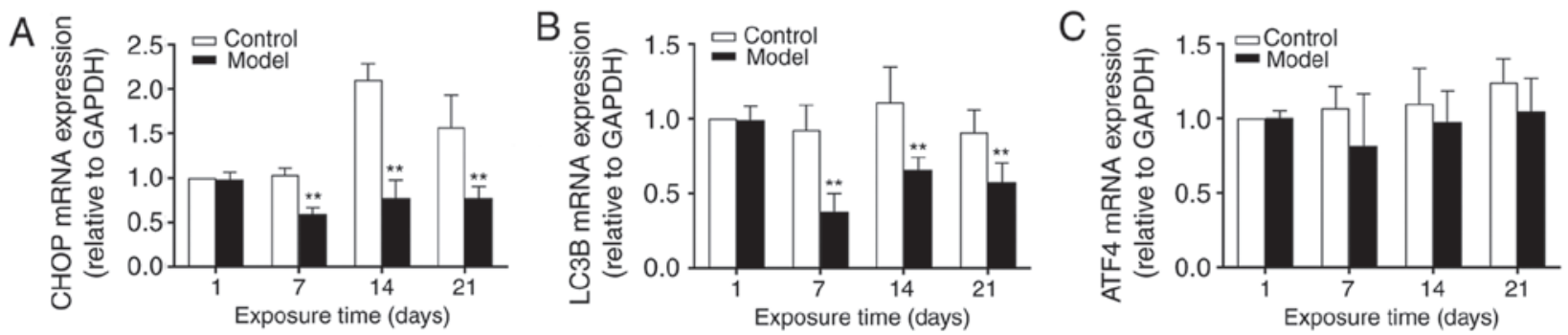

Figure 7. Relative mRNA expression levels of (A) CHOP, (C) ATF4 and (B) LC3B in lung tissues. Compared with the control group, mRNA expression levels of $\mathrm{CHOP}$ and LC3B in the model group were decreased at 7,14 and 21 days, respectively $(\mathrm{P}<0.01) .{ }^{*} \mathrm{P}<0.01$, compared with the control group. C/EBP homologous protein; LC3B, microtubule-associated protein light chain 3 $\beta$; ATF4, activating transcription factor 4.
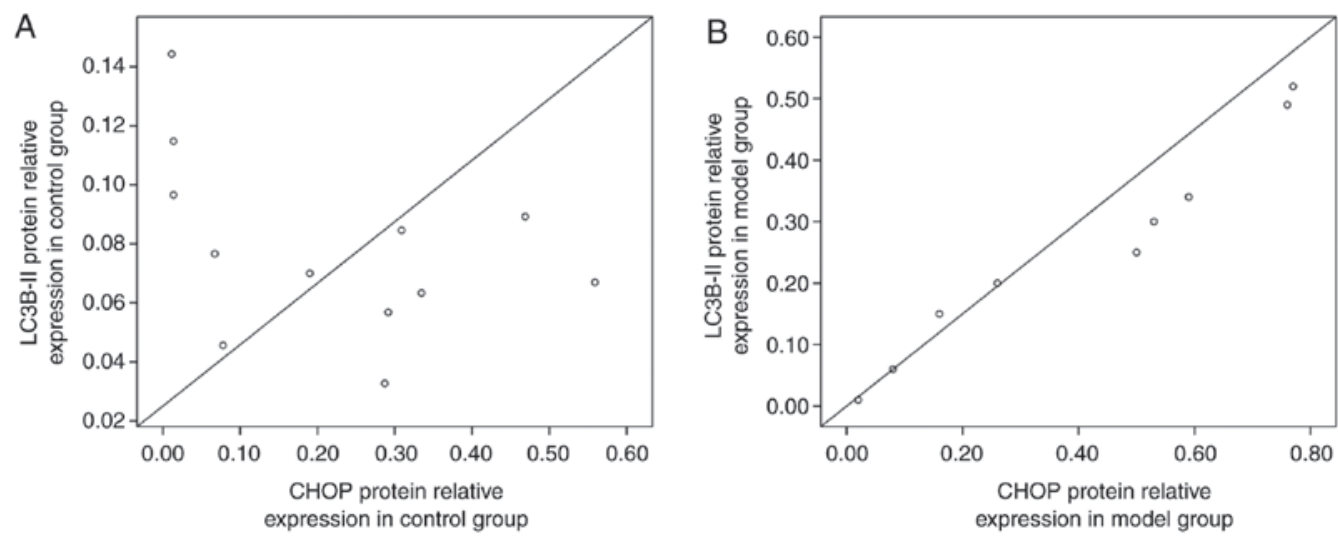

Figure 8. (A and B) Correlation between protein expression levels of CHOP and LC3B-II in lung tissues. In the model group, a positive correlation between the protein expression levels of CHOP and LC3B-II was present. C/EBP homologous protein; LC3B, microtubule-associated protein light chain 3ß.

mRNA expression levels of ATF4, CHOP and LC3B in rat lung tissues. No significant differences were observed in the mRNA expression of ATF4 between the control and model groups $(\mathrm{P}>0.05)$. In the control group, the mRNA expression level of CHOP reached a peak at 14 days and remained high at 21 days. In the model group, the mRNA expression of CHOP remained low with hyperoxic exposure. At 7, 14 and 21 days, significant differences between the control and model groups were noted $(\mathrm{P}<0.01)$. The mRNA expression level of LC3B (an autophagic marker) remained high in the control group. In the model group, it reached a trough at 7 days and was marginally increased at 14 and 21 days, but remained significantly lower than that in the control group. At 7, 14 and 21 days, significant differences were observed between control and model groups $(\mathrm{P}<0.01)$ (Fig. 7A-C).

Analysis of the correlation between the protein expression of CHOP and LC3B-II in rat lung tissues. At 14 days, the correlation between the protein expression of CHOP and LC3B-II was analyzed. Pearson's correlation analysis showed that there was a significant positive correlation between the protein expression levels of CHOP and LC3B-II in the model group $\left(\mathrm{r}^{2}=0.9998, \mathrm{P}<0.01\right)$, and a significant positive correlation in the control group $\left(\mathrm{r}^{2}=0.9981, \mathrm{P}<0.05\right)$ (Fig. 8A and $\left.\mathrm{B}\right)$.

\section{Discussion}

BPD is a common chronic respiratory disease in premature infants. The morbidity rate of BPD associated with oxygen therapy remains high in VLBW and in extremely low birth weight (ELBW) infants. This is despite technological advances and increased salvage levels in the treatment of premature infants, improvements in the technology used in neonatal intensive care units, the popularity of protective assisted ventilation strategies, and increased developments in the prenatal application of glucocorticoids and the postnatal application of PS. BPD now has more mild pathological changes than previously and is known as 'new BPD'. Various studies have differed in their reports of BPD morbidity rates, which may be due to differing clinical definitions of BPD and differences in patient demographics. The incidence rate of BPD is inversely proportional to birth weight and gestational age. More specifically, the severity of BPD decreases with gestational age, and the probability of VLBW and ELBW infants developing BPD is reported to be up to $25-35 \%$ (26). A prospective study completed by the National Institute Child Health and Human Development on newborn infants enrolled between October 2000 and June 2002 with a birth weight of 501-1,249 $\mathrm{g}$ found that the prevalence of BPD was $25-35 \%$ (27). Similarly, American demographic data on 4,200,000 newborn infants in 2008 found that VLBW infants accounted for $1.46 \%$; VLBW and ELBW infants who finally developed BPD accounted for 20-35\% (28). In addition, compared with full-term infants, VLBW/ELBW infants have a higher mortality rate. BPD has been reported to induce several respiratory complications over the longer term and increase the readmission rate of patients, which was reported to be two times higher than that of non-BPD patients (29-33). In adolescence, the reserve 
function, neural development status and growth limitation of patients with BPD (34) cause an increased demand for outpatient services (35). Presently, BPD treatment and its relevant medical difficulties remain a substantial challenge for the parents of patients and the medical industry (36); a number of studies have confirmed that the pathological changes of hyperoxia-induced BPD models comply with the characteristics of new BPD in premature infants, and the establishment of BPD in rats has been demonstrated in numerous studies $(37,38)$.

In the present study, based on domestic and overseas newborn rat models of hyperoxia-induced BPD, the following were observed: Gradual thickening of alveolar walls, a decrease in the number of alveoli, but an increase in the volume of alveoli with structural simplifications, the interrupted formation of secondary alveolar septa, a decreased RAC, and a markedly increased alveolar septum thickness. The above findings indicated the arrest of alveolar development, which is coincident with the characteristics of pulmonary maldevelopment in new BPD. These results are consistent with the results of our previous studies $(37,38)$.

Numerous studies have demonstrated that OS is a key link in the occurrence of BPD (39-41). For example, Abdel Ghany et al (39) reported in a study of 200 neonates that, compared with full-term infants, levels of antioxidant vitamins $\mathrm{A}$ and $\mathrm{E}$ and hydrogen peroxidase, and the overall anti-oxidative level were markedly decreased in premature infants. Additionally, the level of malondialdehyde, a lipid peroxidation marker, was markedly increased, whereas that of vitamin A promoted cell differentiation and the synthesis of surfactants $(42,43)$. Other studies have revealed that a higher dose of vitamin A administered enterally in premature infants may decrease the incidence rates of BPD, intraventricular hemorrhage and necrotizing enterocolitis, and improve prognosis (39). The resuscitation of premature infants with a hypoxic strategy can reduce the demand for respiratory support, the expression of OS markers and the morbidity rate of BPD (44). The levels of total hydrogen peroxide, oxidative protein products and non-protein-bound iron in the umbilical cord blood have shown a significant positive correlation with the prevalence of BPD (45). A hyperoxic environment leads to the marked aggregation of ROS and thus triggers OS, with OS and ROS in a mutually causal relationship.

Wang et al found in their study of HepG2 cells that surfactin induced the production of ROS to thus induce ERS (46). In a study of atherosclerosis, Toma et al observed that the intracellular ROS level was decreased if human endothelial cells cultured with saccharified low density lipoprotein were treated using the ERS inhibitors salubrinal and polychlorobenzoic acid, whereas the intracellular level of ERS was lowered if the cells were treated using the antioxidant, $\mathrm{N}$-acetylcysteine (47).

A number of the aforementioned studies have suggested an association between ERS and ROS (46-49). For example, ERS can also induce the production of ROS. Increased ATP is consumed when the ER folds proteins; however, ATP consumption triggers incorrect protein folding and elevates the oxidative phosphorylation level of mitochondria, thus increasing the production of ATP and ROS. The ER is a $\mathrm{Ca}^{2+}$ bank and unfolded proteins, which accumulate in the ER, can induce a $\mathrm{Ca}^{2+}$ imbalance, with $\mathrm{Ca}^{2+}$ released into the ER lumen. The $\mathrm{Ca}^{2+}$ released into the cytoplasm can then produce ROS via an inositol triphosphate receptor $(48,49)$, thus causing OS. It is crucial for a cell defense response to maintain the dynamic balance between the ER and cytoplasm, in which the transmission of ER signals has a dominant role.

In a rat ischemia-reperfusion brain injury model, the protective effect of hydrogen-rich water was found to be associated with a decrease in oxidative products and an increase in AOEs. In addition, with an increase in the activity of GRP78, a molecular chaperone (50), and a decrease in the activity of $\mathrm{CHOP}$, hydrogen-rich water significantly improved the survival rate and neurological function of rats (51). Tabas and Ron and Marciniak et al identified that the ERS-associated factor, CHOP, was also involved in regulating OS $(52,53)$. Song et al noted that, following knockout of the CHOP gene, the OS of islet $\beta$ cells declined, whereas the antioxidant protein-encoding capacity and antioxidant function improved (54). Han et al found in a chromatin immunoprecipitation experiment that CHOP and ATF4 were able to bind the promoter region of protein synthesis-promoting genes by interaction, and induced the increased synthesis of proteins; however, if occurring prior to the recovery of an ER internal steady state, the increased synthesis of proteins triggered OS and led to an increase in the aggregation of ROS (55). The above findings further suggest that ERS is closely associated with OS.

In the present study, hyperoxic treatment resulted in the production of ROS during the establishment of a BPD newborn rat model; ROS may induce cell death, influence the alveolation process, and cause lung injury and abnormal injury repair (56). AECII cells are the major cells attacked by ROS in hyperoxia-induced lung injury (41); they are rich in ER, and thus have the conditions and foundation for the occurrence of ERS. Previously, it was found that, in addition to necrosis, apoptosis and transdifferentiation, the ultrastructure of AECII cells changed during BPD lung injury. For example, microvilli were detached and sparse, nuclear chromatin became marginally aggregated, lamellar bodies became damaged and vacuolized, and mitochondria became swollen. In the present study, it was also observed that the ER, which had a laminar structure under physiological conditions, became markedly dilated, pool-shaped and degranulated; surrounding APs were sparsely distributed. This suggested that ERS is somewhat associated with autophagy in OS. ERS and autophagy are two important pathways of cell protein degradation. The latest data show that ERS adapts to endogenous and exogenous pressures by strengthening its protein folding capacity and activating protective mechanisms, including autophagy and an antioxidant response.

In addition to calcium storage, the ER is an important organelle for protein synthesis, whereby newly synthesized proteins are folded into mature proteins in the ER lumen, and then transferred to the cytoplasm or out of cells. Under several physiological or pathological conditions, including hypoxia, viral infection and ischemia, the intracellular steady state of the ER is damaged and dysfunction occurs. This leads to a metabolic imbalance of carbohydrates and lipids, and a disturbance in calcium balance in the ER, in addition to a change in the environment of the ER lumen for redox reactions. Such a change of the internal environment leads to the incorrect folding and maturation of proteins, thus causing the 
aggregation of incorrectly folded/unfolded proteins in the ER lumen, leading to a failure in the effective output of proteins and eventually inducing ERS (57,58). The imbalance between oxidation and anti-oxidative defense capacity keeps cells in an OS state, whereas the ROS produced by OS can attach to the organelle membrane to induce a peroxidative injury, an important factor in causing incorrect protein folding in the ER and thus inducing ERS. ERS is involved in proinflammatory signaling, the apoptosis of AECs, and the transdifferentiation of epithelial to mesenchymal cells.

CHOP, being downstream of ATF4, is an ERS-specific transcriptional factor. The expression levels of ATF4 and CHOP were significantly increased in the presence of ERS, and the formation of ERS was inhibited when CHOP was knocked down in the cells (59). In the ERS pathway, activated CHOP mediates LPS-induced lung injury (60); the overexpression of CHOP in renal cells and podocytes causes an increase in the production of ROS, indicating that CHOP is involved in OS (61). In a previous study, Lozon et al found that, when MLE-12 cells were exposed to $95 \% \mathrm{O}_{2}$ for $24 \mathrm{~h}$, the protein expression of CHOP increased. In $\mathrm{CHOP}^{-/}$mice, pneumonedema and increased permeability occurred under a hyperoxic environment, which suggested that $\mathrm{CHOP}$ may have a protective role in an oxidizing environment (62). Choo-Wing et al showed that hyperoxic stimulation in a BPD mouse model led to a marked increase in the protein and mRNA expression levels of $\mathrm{CHOP}$, in vitro and in vivo. The knockout of CHOP by siRNA was found to reduce mouse MLE-12 cell death and relieve hyperoxia-induced alveolation disorders. Coincidently, CHOP levels were increased in the lung tissues of patients with BPD (63). Lu et al demonstrated that the protein level of CHOP was significantly increased during hyperoxic exposure (64).

In the present study, it was found that the protein levels of ATF4 and CHOP in the model group were higher compared with those in the control group at 7 days, which was consistent with the study results of Choo-Wing et al (63) and Lu et al (64) The protein expression level of $\mathrm{CHOP}$ reached a peak at 14 days and was marginally decreased at 21 days in the present study, whereas it was continuously increased in the study of Lu et al. One possible cause for this difference may be that premature rats were delivered by cesarean section at day 21 of gestation in the model used by Lu et al, whereas the newborn rats were delivered spontaneously at 22 days of gestation in the present study. Such a difference in the premature reduction of the protein expression level of CHOP may be attributed to the varying anti-oxidative defense capacity of individuals. No significant difference was found in mRNA expression level of ATF4 between the control and model groups. The mRNA expression level of CHOP was significantly higher in the control group, compared with that in the model group. This differs from the results of the above study on the protein expression level of CHOP, and the high protein expression of $\mathrm{CHOP}$ induced by ERS can promote apoptosis. Several studies have shown that minimal CHOP protein is expressed in normal tissues and cells (65). Therefore, the differential protein and mRNA expression of CHOP may be regulated not at the gene level, but at a post-transcriptional level, by, for example, via shortening of protein half-life, enzyme degradation or mRNA regulation.
In the present study, it was revealed by TEM that, compared with the control group, the morphology and organelle structure of AECII cells were seriously damaged; the ER was dilated and surrounded by marginally aggregated APs with a double-layer membrane, Autophagy of AECII cells in the model group was also noted at day 14. This intuitively indicates that ERS and autophagy co-exist in AECII cells. Studies have shown that autophagy has a specific function in AECII cells, namely, it is involved in the synthesis of pulmonary surfactants. CHOP is a recognized mediator of apoptosis; however, a previous study suggested that CHOP promoted a survival-promoting autophagic process via synergistic reaction with ATF4 (66). LC3B-II is a key protein for the maturation of APs; following the activation of autophagy, the autophagic marker LC3B-I forms LC3B-II by esterified coupling with phosphatidylethanolamine. LC3B-II then translocates to the membrane of APs, with the level of LC3B-II reflecting the number of APs to a certain degree (67). Zhang et al identified that, with the prolongation of hyperoxic exposure time, the level of LC3B-II was markedly increased. The AECII-to-AECI transdifferentiation capacity is partially restored by suppressing the level of LC3B-II (21).

The present study revealed that the protein expression level of LC3B-II in the model group was significantly higher, compared with that in the control group at 7 days, and reached a peak at 14 days, which coincided with the study results of Zhang et al, who did not investigate a 21-day group. In the present study, following 21 days of hyperoxic exposure, the level of autophagy was decreased or suppressed. In addition, observations at a gene level showed that the mRNA expression level of LC3B was markedly lower in the model group, compared with that in the control group at $\geq 7$ days. This suggested that autophagy/autophagic flow, or post-transcriptional regulation may have been suppressed. It is generally considered that the formation and degradation of APs are in a dynamic balance, and when such a balance is damaged, if the degradation of APs is limited or autophagy is suppressed, it affects the production of APs to a certain extent. Autophagy, as an outlet of ERS, is one of the important pathways for protein degradation in cells, and can increase the threshold for the promotion of apoptosis in the dual effects of ERS and reduce the pressure load of cells. The suppression of autophagic flow can increase the aggregation of proteins and worsen ERS (68-70).

Previous studies have suggested that there is an association between ERS and autophagy. These two systems may be mutually independent in function, but have a dependent association in regulation; changing the activity of one system may influence the other. According to previous studies, continuous ERS may increase the activity of autophagy (71), whereas autophagy may alleviate ERS by eliminating unfolded proteins; in contrast, interrupting autophagy may worsen ERS (72,73). However, there have been few studies on the association between autophagy and ERS in BPD. A series of electron microscopic results have provided evidence for the role of the ER membrane in the formation and maturation of APS. The immunoelectron microscopy study by Dunn showed that APs acquired lysosomal markers from the ER during their formation and gradual maturation (74). Ueno et al found that, following treatment with leupeptin, an ER membrane marker was present on the vesicle membrane of APs isolated 
from the rat liver (75). Bernale et al observed a dilated ER with the formation of AP-like structures, and that intensive and selective enclosure was from the membrane components of the UPR (71). Axe et al noted that AP formation from membrane compartments was enriched in phosphatidylinositol 3-phosphate and dynamically connected to the ER, which showed a close association between the formation of APs and the ER (76). Hart et al suggested that at least part of the membrane of APs was derived from the ER membrane (77).

Using TEM and immunofluorescence techniques, the present study observed the co-presence of ERS and autophagy in AECII cells, and the aggregation of APs surrounding dilated ER. In the model group, CHOP and LC3B were simultaneously increased at 7 days, and reached a peak at 14 days, indicating a simultaneous increase of ERS and levels of autophagy during hyperoxic exposure. Peaks formed at the same time, and an almost consistent change in trend suggested that CHOP and LC3B may influence and promote each other, and be mutually dependent.

A previous chromatin immunoprecipitation experiment demonstrated that ATF4 and CHOP directly induce the transcriptional expression of autophagy (Atg)-related genes Atg10, Atg5, p62 and Atg7 by binding with the GTGCAACC region of cis-acting elements in the promoters of these genes. These genes have a non-negligible role in the formation, prolongation and functional maintenance of autophagosomes (78). Based on previous reports, ATF4 and CHOP have a targeted effect on LC3B-II and Atg5 via the PKR-like endoplasmic reticulum kinase-eIF2a pathway $(79,80)$.

The high protein expression level of CHOP is associated with the esterification capacity of $\mathrm{LC} 3 \mathrm{~B}$, and can promote the transformation of LC3B-I to LC3B-II (78). Another study demonstrated that autophagy regulated the transcription of $\mathrm{CHOP}$, and that $\mathrm{CHOP}$ promoted survival via autophagy (66) to offset excessive UPR signals, which further suggests a possible co-dependent association between CHOP and autophagy. However, the present study found that, at 21 days, the level of CHOP in the model group was higher, compared with that in the control group, whereas the level of LC3B was lower. This suggested that the autophagosome elimination pathway may be inhibited in this phase, causing the suppression of autophagic flow and the inability of cells to degrade proteins via an autophagy pathway. As a result, the expression level of CHOP was continuously high, but remained lower, compared with that at day 14. This further indicated that CHOP and LC3B may have a mutually dependent relationship, which is consistent with the views of $\mathrm{Xu}$ et al (81) as well as the views of other studies (82-84). Their views were specifically as follows: There is an interaction between ERS and autophagy; continuous ERS can increase autophagic activity; autophagy may alleviate ERS by eliminating unfolded proteins, and, in contrast, interrupting autophagy may increase ERS. The double immunofluorescence staining in the present study showed that $\mathrm{CHOP}$ and LC3B were co-expressed in the model group at day 14. Analysis at this time-point showed a positive correlation between CHOP and LC3B in the control and model groups. This further supported the above views.

Taken together, the results of the present study suggested that hyperoxic stimulation activated ERS and autophagy. The AECII cells of newborn rats under hyperoxic exposure exhibited dilated, pool-shaped ER and APs containing ER and other organelles. In addition, $\mathrm{CHOP}$ and LC3B were overexpressed and correlated with each other, with both increasing and reaching a peak at the same time. This suggested that ERS and autophagic activation may be associated with and regulate the occurrence and development of BPD. This may be a novel and potential method to treat hyperoxia-induced BPD effectively in clinic, by adjusting the balance of ERS and autophagy. However, the specific mechanisms involved in ERS and autophagy under hyperoxic conditions were not investigated in the present study; these mechanisms require further investigation.

\section{Acknowledgements}

The authors would like to thank Liu Dongyan and Miao Jianing for their excellent technical assistance.

\section{Funding}

This study was supported by the National Natural Science Foundation of China (grant no. 81571479) and the Key laboratory of basic research projects in Liaoning province Department of Education (grant no. LZ2015070).

\section{Availability of data and materials}

The datasets used and/or analyzed during the current study are available from the corresponding author on reasonable request.

\section{Authors' contributions}

ML was involved in drafting the manuscript or revising it critically for important intellectual content. BP collected the rat lung tissue and made contributions to the bronchopulmonary dysphasia rat model. YS made contributions to analysis and interpretation of data. JF made contributions to the conception and design of the project. XX gave final approval of the version to be published.

\section{Ethics approval and consent to participate}

All animal experiments were approved by the Animal Ethics Committee of China Medical University (no. 2015PS230K), and all surgical procedures were performed under anesthesia with chloral hydrate to minimize pain of the experimental animals.

\section{Patient consent for publication}

Not applicable.

\section{Competing interests}

The authors declare that they have no competing interests.

\section{References}

1. Isayama T, Lee SK, Mori R, Kusuda S, Fujimura M, Ye XY and Shah PS; Canadian Neonatal Network, Neonatal Research Network of Japan: Comparison of mortality and morbidity of very low birth weight infants between Canada and Japan. Pediatrics 130: e957-e965, 2012. 
2. Silva DM, Nardiello C, Pozarska A and Morty RE: Recent advances in the mechanisms of lung alveolarization and the pathogenesis of bronchopulmonary dysplasia. Am J Physiol Lung Cell Mol Physiol 309: L1239-L1272, 2015.

3. Dani $\mathrm{C}$ and Poggi C: The role of genetic polymorphisms in antioxidant enzymes and potential antioxidant therapies in neonatal lung disease. Antioxid Redox Signal 21: 1863-1880, 2014.

4. Gitto E, Pellegrino S, D'Arrigo S, Barberi I and Reiter RJ: Oxidative stress in resuscitation and ventilation of newborns. Eur Respir J 34: 1461-1469, 2009.

5. Perrone S, Negro S, Tataranno ML and Buonocore G: Oxidative stress and antioxidant strategies in newborns. J Matern Fetal Neonatal Med Suppl 3: 63-65, 2010.

6. Perrone S, Tataranno ML and Buonocore G: Oxidative stress and bronchopulmonary dysplasia. J Clin Neonatol 1: 109-114, 2012.

7. Wang X, Li W, Liu W, Cai B, Cheng T, Gao C, Mo L, Yang H and Chang L: GSTM1 and GSTT1 gene polymorphisms as major risk factors for bronchopulmonary dysplasia in a Chinese Han population. Gene 533: 48-51, 2014.

8. Hsiao CC, Chang JC, Tsao LY, Yang RC, Chen HN, Lee CH, Lin CY and Tsai YG: Correlates of elevated interleukin- 6 and 8-Hydroxy-2'-Deoxyguanosine levels in tracheal aspirates from very low birth weight infants who develop bronchopulmonary dysplasia. Pediatr Neonatol 58: 63-69, 2017.

9. Fabiano A, Gavilanes AW, Zimmermann LJ, Kramer BW, Paolillo P, Livolti G, Picone S, Bressan K and Gazzolo D: The development of lung biochemical monitoring can play a key role in the early prediction of bronchopulmonary dysplasia. Acta Paediatr 105: 535-541, 2016.

10. Kaya G, Saldir M, Polat A, Fidanci MK, Erdem A, Erdem G, Kurt YG, Cetinkaya M, Cekmez F, Onguru O and Tunc T: Evaluation of etanercept treatment in newborn rat model with hyperoxic lung injury. Fetal Pediatr Pathol 35: 327-338, 2016.

11. Görlach A, Klappa P and Kietzmann T: The endoplasmic reticulum: Folding, calcium homeostasis, signaling, and redox control. Antioxid Redox Signal 8: 1391-1418, 2006.

12. Tu BP and Weissman JS: Oxidative protein folding in eukaryotes: Mechanisms and consequences. J Cell Biol 164: 341-346, 2004.

13. Sevier CS and Kaiser CA: Erol and redox homeostasis in the endoplasmic reticulum. Biochim Biophys Acta 1783: 549-556, 2008 .

14. YounceCW,Wang KandKolattukudyPE:Hyperglycaemia-induced cardiomyocyte death is mediated via MCP-1 production and induction of a novel zinc-finger protein MCPIP. Cardiovasc Res 87: 665-674, 2010

15. Rothermel BA and Hill JA: Myocyte autophagy in heart disease: Friend or foe? Autophagy 3: 632-634, 2007.

16. Takemura G, Miyata S, Kawase Y, Okada H, Maruyama R and Fujiwara H: Autophagic degeneration and death of cardiomyocytes in heart failure. Autophagy 2: 212-214, 2006.

17. Jian X, Xiao-yan Z, Bin H, Yu-feng Z, Bo K, Zhi-nong W and Xin N: MiR-204 regulate cardiomyocyte autophagy induced by hypoxia-reoxygenation through LC3-II. Int J Cardiol 148: 110-112, 2011.

18. Wang C,Li YZ, Wang XR,Lu ZR,ShiDZ and Liu XH: Panax quinquefolium saponins reduce myocardial hypoxia-reoxygenation injury by inhibiting excessive endoplasic reticulum stress. Shock 37: 228-233, 2012

19. Fan T, Huang Z, Chen L, Wang W, Zhang B, Xu Y, Pan S, Mao Z, Hu H and Geng Q: Associations between autophagy, the ubiquitin-proteasome system and endoplasmic reticulum stress in hypoxia-deoxygenation or ischemia-reperfusion. Eur J Pharmacol 791: 157-167, 2016.

20. Zhang L, Zhao S, Yuan LJ, Wu HM, Jiang H, Zhao SM, Luo G and Xue XD: Autophagy regulates hyperoxia-induced intracellular accumulation of surfactant protein $\mathrm{C}$ in alveolar type II cells. Mol Cell Biochem 408: 181-189, 2015.

21. Zhang L, Zhao S, Yuan L, Wu H, Jiang $\mathrm{H}$ and Luo G: Hyperoxia-mediated LC3B activation contributes to the impaired transdifferentiation of type II alveolar epithelial cells (AECIIs) to type I cells (AECIs). Clin Exp Pharmacol Physiol 43: 834-843, 2016.

22. You K, Xu X, Fu J, Xu S, Yue X, Yu Z and Xue X: Hyperoxia disrupts pulmonaryepithelial barrier in newborn rats via the deterioration of occludin and ZO-1. Respir Res 13: 36, 2012.

23. Cooney TP and Thurlbeck WM: The radial alveolar count method of Emery and Mithal: A reappraisal 1-postnatal lung growth. Thorax 37: 572-579, 1982 .
24. Hou A, Fu J, Yang H, Zhu Y, Pan Y, Xu S and Xue X: Hyperoxia stimulates the transdifferentiation of type II alveolar epithelial cells in newborn rats. Am J Physiol Lung Cell Mol Physiol 308: L861-L872, 2015.

25. Livak KJ and Schmittgen TD: Analysis of relative gene expression data using real-time quantitative PCR and the 2(-delta delta $\mathrm{C}(\mathrm{T})$ ) method. Methods 25: 402-408, 2001.

26. Abman SH and Groothius JR: Pathophysiology and treatment of bronchopulmonary dysplasia. Current issues. Pediatr Clin North Am 41: 277-315, 1994

27. Walsh MC, Yao Q, Gettner P, Hale E, Collins M, Hensman A, Everette R, Peters N, Miller N, Muran G, et al: Impact of a physiologic definition on bronchopulmonary dysplasia rates. Pediatrics 114: 1305-1311, 2004.

28. Martin JA, Hamilton BE, Sutton PD, Ventura SJ, Mathews TJ and Osterman MJ: Births: Final data for 2008. Natl Vital Stat Rep 59: 1, 3-71, 2010.

29. Chien YH, Tsao PN, Chou HC, Tang JR and Tsou KI: Rehospitalization of extremely-low-birth-weight infants in first 2 years of life. Early Hum Dev 66: 33-40, 2002.

30. Doyle LW, Ford G and Davis N: Health and hospitalisations after discharge in extremely low birth weight infants. Semin Neonatol 8: 137-145, 2003.

31. Lamarche-Vadel A, Blondel B, Truffer P, Burguet A, Cambonie G, Selton D, Arnaud C, Lardennois C, du Mazaubrun C, N'Guyen S, et al: Rehospitalization in infants younger than 29 weeks' gestation in the EPIPAGE cohort. Acta Paediatr 93: $1340-1345,2004$

32. Luu TM, Lefebvre F, Riley P and Infante-Rivard C: Continuing utilisation of specialised health services in extremely preterm infants. Arch Dis Child Fetal Neonatal Ed 95: F320-F325, 2010.

33. Smith VC, Zupancic JA, McCormick MC, Croen LA, Greene J, Escobar GJ and Richardson DK: Rehospitalization in the first year of life among infants with bronchopulmonary dysplasia. J Pediatr 144: 799-803, 2004.

34. Broström EB, Thunqvist P, Adenfelt G, Borling E and Katz-Salamon M: Obstructive lung disease in children with mild to severe BPD. Respir Med 104: 362-370, 2010.

35. Hintz SR, Kendrick DE, Vohr BR, Poole WK and Higgins RD; National institute of child health and human development (NICHD) neonatal research network: Community supports after surviving extremely low-birthweight, extremely preterm birth Special outpatient services in early childhood. Arch Pediatr Adolesc Med 162: 748-755, 2008.

36. Groothuis JR and Makari D: Definition and outpatient management of the very low-birth-weight infant with bronchopulmonary dysplasia. Adv Ther 29: 297-311, 2012

37. Yang H, Fu J, Xue X, Yao L, Qiao L, Hou A, Jin L and Xing Y: Epithelial-mesenchymal transitions in bronchopulmonary dysplasia of newborn rats. Pediatr Pulmonol 49: 1112-1123, 2014.

38. Hou A, Fu J, Shi Y, Qiao L, Li J, Xing Y and Xue X: Decreased ZONAB expression promotes excessive transdifferentiation of alveolar epithelial cells in hyperoxia-induced bronchopulmonary dysplasia. Int J Mol Med 41: 2339-2349, 2018.

39. Abdel Ghany EA, Alsharany W, Ali AA, Younass ER and Hussein JS: Anti-oxidant profiles and markers of oxidative stress in preterm neonates. Paediatr Int Child Health 36: 134-140, 2016.

40. Jobe AH and Bancalari E: Bronchopulmonary dysplasia. Am J Respir Crit Care Med 163: 1723-1729, 2001.

41. Saugstad OD: Oxygen and oxidative stress in bronchopulmonary dysplasia. J Perinat Med 38: 571-577, 2010.

42. Biesalski HK and Nohr D: Importance of vitamin-A for lung function and development. Mol Aspects Med 24: 431-440, 2003.

43. Metzler MD and Snyder JM: Retinoic acid differentially regulates expression of surfactant associated proteins in human fetal lung. Endocrinology 133: 1990-1998, 1993.

44. Vento M, Moro M, Escrig R, Arruza L, Villar G, Izquierdo I, Roberts LJ II, Arduini A, Escobar JJ, Sastre J and Asensi MA: Preterm resuscitation with low oxygen causes less oxidative stress, inflammation and chronic lung disease. Pediatrics 124: e439-e449, 2009.

45. Perrone S, Tataranno ML, Negro S, Longini M, Marzocchi B, Proietti F, Iacoponi F, Capitani S and Buonocore G: Early identification of the risk for free radical-related diseases in preterm newborns. Early Hum Dev 86: 241-244, 2010.

46. Wang CL, Liu C, Niu LL, Wang LR, Hou LH and Cao XH: Surfactin-induced apoptosis through ROS-ERS-Ca ${ }^{2+}$-ERK pathways in HepG2 cells. Cell Biochem Biophys 67: 1433-1439, 2013. 
47. Toma L, Sanda GM, Deleanu M, Stancu CS and Sima AV: Glycated LDL increase VCAM-1 expression and secretion in endothelial cells and promote monocyte adhesion through mechanisms involving endoplasmic reticulum stress. Mol Cell Biochem 417: 169-179, 2016.

48. Malhotra JD and Kaufman RJ: Endoplasmic reticulum stress and oxidative stress: A vicious cycle or a double-edged sword? Antioxid Redox Signal 9: 2277-2293, 2007.

49. Cioffi DL: Redox regulation of endothelial canonical transient receptor potential channels. Antioxid Redox Signal 15: $1567-1582,2011$.

50. Flodby P, Li C, Liu Y, Wang H, Marconett CN, Laird-Offringa IA, Minoo P, Lee AS and Zhou B: GRP78 regulates ER homeostasis and distal epithelial cell survival during lung development. Am J Respir Cel Mol Biol 55: 135-149, 2016.

51. Gao Y, Gui Q, Jin L, Yu P, Wu L, Cao L, Wang Q and Duan M: Hydrogen-rich saline attenuates hippocampus endoplasmic reticulum stress after cardiac arrest in rats. Neurosci Lett 640 29-36, 2017.

52. Tabas I and Ron D: Integrating the mechanisms of apoptosis induced by endoplasmic reticulum stress. Nat Cell Biol 13: 184-190, 2011.

53. Marciniak SJ, Yun CY, Oyadomari S, Novoa I, Zhang Y, Jungreis R, Nagata K, Harding HP and Ron D: CHOP induces death by promoting protein synthesis and oxidation in the stressed endoplasmic reticulum. Genes Dev 18: 3066-3077, 2004.

54. Song B, Scheuner D, Ron D, Pennathur S and Kaufman RJ: Chop deletion reduces oxidative stress, improves beta cell function, and promotes cell survival in multiple mouse models of diabetes. J Clin Invest 118: 3378-3389, 2008.

55. Han J, Back SH, Hur J, Lin YH, Gildersleeve R, Shan J, Yuan CL, Krokowski D, Wang S, Hatzoglou M, et al: ER-stress-induced transcriptional regulation increases protein synthesis leading to cell death. Nat Cell Biol 15: 481-490, 2013.

56. Zhang X, Shan P, Sasidhar M, Chupp GL, Flavell RA, Choi AM and Lee PJ: Reactive oxygen species and extracellular signal-regulated kinase 1/2 mitogen-activated protein kinase mediate hyperoxia-induced cell death in lung epithelium. Am J Respir Cell Mol Biol 28: 305-315, 2003.

57. Cao SS and Kaufman RJ: Targeting endoplasmic reticulum stress in metabolic disease. Expert Opin Ther Targets 17: 437-448, 2013.

58. Roussel BD, Kruppa AJ, Miranda E, Crowther DC, Lomas DA and Marciniak SJ: Endoplasmic reticulum dysfunction in neurological disease. Lancet Neurol 12: 105-118, 2013.

59. Kroemer G and Blomgren K: Mitochondrial cell death control in familial Parkinson disease. PLoS Biol 5: e206, 2007.

60. Endo M, Oyadomari S, Suga M, Mori M and Gotoh T: The ER stress pathway involving CHOP is activated in the lungs of LPS-treated mice. J Biochem 138: 501-507, 2005.

61. Bek MF, Bayer M, Müller B, Greiber S, Lang D, Schwab A, August C, Springer E, Rohrbach R, Huber TB, et al: Expression and function of C/EBP homology protein (GADD153) in podocytes. Am J Pathol 168: 20-32, 2006.

62. Lozon TI, Eastman AJ, Matute-Bello G, Chen P, Hallstrand TS and Altemeier WA: PKR-dependent CHOP induction limits hyperoxiainduced lung injury. Am J Physiol Lung Cell Mol Physiol 300: L422-L429, 2011.

63. Choo-Wing R, Syed MA, Harijith A, Bowen B, Pryhuber G, Janér C, Andersson S, Homer RJ and Bhandari V: Hyperoxia and interferon- $\gamma$-induced injury in developing lungs occur via cyclooxygenase- 2 and theendoplasmic reticulum stress-dependent pathway. Am J Respir Cell Mol Biol 48: 749-757, 2013.

64. Lu HY, Zhang J, Wang QX, Tang W and Zhang LJ: Activation of the endoplasmic reticulum stress pathway involving CHOP in the lungs of rats with hyperoxia-induced bronchopulmonary dysplasia. Mol Med Rep 12: 4494-4500, 2015.

65. Bozi LH, Jannig PR, Rolim N, Voltarelli VA, Dourado PM, Wisløff $U$ and Brum PC: Aerobic exercise training rescues cardiac protein quality control and bluntsendoplasmic reticulum stress in heart failure rats. J Cell Mol Med 20: 2208-2212, 2016.

66. B'Chir W, Chaveroux C, Carraro V, Averous J, Maurin AC, Jousse C, Muranishi Y, Parry L, Fafournoux P and Bruhat A: Dual role for CHOP in the crosstalk between autophagy and apoptosis to determine cell fate in response to amino acid deprivation. Cell Signal 26: 1385-1391, 2014.
67. Kouno T, Mizuguchi M, Tanida I, Ueno T, Kanematsu T, Mori Y, Shinoda H, Hirata M, Kominami E and Kawano K: Solution structure of microtubule-associated protein light chain 3 and identification of its functional subdomains. J Biol Chem 280: 24610-24617, 2005.

68. Schönthal AH: Endoplasmic reticulum stress and autophagy as targets for cancer therapy. Cancer Lett 275: 163-169, 2009.

69. Høyer-Hansen M and Jäättelä M: Connecting endoplasmic reticulum stress to autophagy by unfolded protein response and calcium. Cell Death Differ 14: 1576-1582, 2007.

70. Mathew R, Karantza-Wadsworth V and White E: Role of autophagy in cancer. Nat Rev Cancer 7: 961-967, 2007.

71. Bernales S, McDonald KL and Walter P: Autophagy counterbalances endoplasmic reticulum expansion during the unfolded protein response. PLoS Biol 4: e423, 2006.

72. Cheng Y and Yang JM: Survival and death of endoplasmic-reticulum-stressed cells: Role of autophagy. World J Biol Chem 2: 226-231, 2011.

73. Schleicher SM, Moretti L, Varki V and Lu B: Progress in the unraveling of the endoplasmic reticulum stress/autophagy pathway and cancer: Implications for future therapeutic approaches. Drug Resist Updat 13: 79-86, 2010.

74. Dunn WA Jr: Studies on the mechanisms of autophagy: Formation of the autophagic vacuole. J Cell Biol 110: 1923-1933, 1990.

75. Ueno T, Muno D and Kominami E: Membrane markers of endoplasmic reticulum preserved in autophagic vacuolar membranes isolated from leupeptin-administered rat liver. J Biol Chem 266: 18995-18999, 1991

76. Axe EL, Walker SA, Manifava M, Chandra P, Roderick HL, Habermann A, Griffiths G and Ktistakis NT: Autophagosome formation from membrane compartments enriched in phosphatidylinositol 3-phosphate and dynamically connected to the endoplasmic reticulum. J Cell Biol 182: 685-701, 2008.

77. Hart LS, Cunningham JT, Datta T, Dey S, Tameire F, Lehman SL, Qiu B, Zhang H, Cerniglia G, Bi M, et al: ER stress-mediated autophagy promotes Myc-dependent transformation and tumor growth. J Clin Invest 122: 4621-4634, 2012.

78. B'chir W, Maurin AC, Carraro V, Averous J, Jousse C, Muranishi Y, Parry L, Stepien G, Fafournoux P and Bruhat A: The eIF $2 \alpha /$ ATF4 pathway is essential for stress-induced autophagy gene expression. Nucleic Acids Res 41: 7683-7699, 2013.

79. Rouschop KM, van den Beucken T, Dubois L, Niessen H, Bussink J, Savelkouls K, Keulers T, Mujcic H, Landuyt W and Voncken JW: The unfolded protein response protects human tumor cells during hypoxia through regulation of the autophagy genes MAP1LC3B and ATG5. J Clin Invest 120: 127-141, 2010.

80. Avivar-Valderas A, Salas E, Bobrovnikova-Marjon E, Diehl JA, Nagi C, Debnath J and Aguirre-Ghiso JA: PERK integrates autophagy and oxidative stress responses to promote survival during extracellular matrix detachment. Mol Cell Biol 31: 3616-3629, 2011

81. Xu Y, Yu H, Qin H, Kang J, Yu C, Zhong J, Su J, Li H and Sun L: Inhibition of autophagy enhances cisplatin cytotoxicity through endoplasmic reticulum stress in human cervical cancer cells. Cancer Lett 314: 232-243, 2012.

82. Kouroku Y, Fujita E, Tanida I, Ueno T, Isoai A, Kumagai H, Ogawa S, Kaufman RJ, Kominami E and Momoi T: ER stress (PERK/eIF2alpha phosphorylation) mediates the polyglutamine-induced LC3 conversion, an essential step for autophagy formation. Cell Death Differ 14: 230-239, 2007.

83. Nijholt DA, de Graaf TR, van Haastert ES, Oliveira AO, Berkers CR, Zwart R, Ovaa H, Baas F, Hoozemans JJ and Scheper W: Endoplasmic reticulum stress activates autophagy but not the proteasome in neuronal cells: Implications for Alzheimer's disease. Cell Death Differ 18: 1071-1081, 2011.

84. Adolph TE, Tomczak MF, Niederreiter L, Ko HJ, Böck J, Martinez-Naves E, Glickman JN, Tschurtschenthaler M, Hartwig J, Hosomi S, et al: Paneth cells as a site of origin for intestinal inflammation. Nature 503: 272-276, 2013. 